\title{
The Implementation of Discharge Planning In Regional General Hospital: Nurses Perceived
}

\author{
Ardia Putra ${ }^{1}$, Nelly Safrina ${ }^{2}$, Hajjul Kamil ${ }^{3}$, Yuswardi ${ }^{4}$, Budi Satria ${ }^{5}$ \\ ${ }^{1,3,4}$ Fundamental \& Management of Nursing Department, Faculty of Nursing, Universitas Syiah Kuala, Banda Aceh, Indonesia \\ ${ }^{2}$ Nursing Staff at Pidie Jaya District Hospital, Pidie Jaya, Indonesia \\ ${ }^{5}$ Community of Nursing Department, Faculty of Nursing, Universitas Syiah Kuala, Banda Aceh, Indonesia
}

\begin{abstract}
Discharge planning is a nursing service provided to prepare patients for independent care after leaving the health care facility. Nurses have a significant role in the implementation of discharge planning. Failure to provide and document discharge planning will risk the severity of the disease, lifethreatening, and physical dysfunction. The purpose of this study was to describe the nurse's perception of the importance of discharge planning in the Inpatient Room at the RSUDZA Banda Aceh. This descriptive study used a cross-sectional approach, and the population is all nurses who work in the Inpatient Room RSUDZA Banda Aceh. The sampling technique in this study was simple random sampling, with a total of 61 respondents. The data collection tool is a questionnaire using a Likert scale consisting of 33 statements and data analysis in univariate analysis. The results showed that from 61 respondents, $67.2 \%$ of respondents perceived discharge planning as important to implement. The result for each variable is described simultaneously: $62.3 \%$ of respondents perceive medication as "important" to implement; then $63.9 \%$ of respondents perceive the environment as "less important" to be implemented; moreover, $82.0 \%$ of respondents perceive treatment as "important" to implement; continued by $65.6 \%$ of respondents perceive Health Teaching is "less important" to implement; 86.9\% of respondents perceive Outpatient Referrals as "important" to implement; lastly, 73.8\% of respondents perceive diet as "important" to implement. It is recommended that the hospital improve the quality of hospital services significantly in discharge planning by making guides/permanent procedures for implementing discharge planning to patients.
\end{abstract}

Key words: Discharge planning, Nurse, Perception, Hospitalization, Inpatient room.

\section{INTRODUCTION}

$\mathrm{H}$ ospital is one of the health service delivery systems, providing services using a multidisciplinary concept. A multidisciplinary concept is a collaboration between medical, nurses, nutrition, physiotherapy, pharmacy, and support to provide the best service to the community. Nurses are health workers who have significant contributions in improving health services in hospitals because nurses have the longest time interacting with patients and families (Hariyati et al., 2008, p. 53).

Nursing service is a form of professional service that is an integral part of health services based on nursing knowledge and tips in comprehensive biological, psychological, sociological, and spiritual services. Nursing aims to individuals, families, and communities in good health and illness, covering the entire human life process (Kusnanto, 2004, p. 29). In providing nursing services, nurses must provide professional services by mobilizing their best abilities and skills to benefit health service recipients.

The community still reports many complaints regarding health services in hospitals that are less than optimal. One service activity that is not yet optimal is implementing discharge planning (Hariyati et al., 2008). Discharge planning is an integral part of service to patients and families that begins when the patient enters the hospital and enters the rehabilitation stage. Discharge planning is a process of describing cooperation between the health team, families, patients, and influential people for patients starting from the assessment, planning, implementation, and evaluation stages (Potter \& Perry, 2012).

Since the patient enters the hospital, the discharge planning program can improve health conditions and help patients achieve optimum quality of life before being discharged. Ignorance or inability of the patient and family regarding how to care at home impacts health problems or the patient's unpreparedness to face discharge after the patient is hospitalized. This situation can cause an increased risk of complications and results in re-hospitalization (Potter \& Perry, 2012). Failure to provide and document discharge planning will risk the severity of the disease, life-threatening, and physical dysfunction. Discharge planning can reduce the day or length of patient care, prevent a recurrence, improve the patient's health condition, reduce the burden on the patient's family and reduce mortality and morbidity. The implementation of good discharge planning will improve the patient's health quality (Nursalam, 2014). Perception is how individuals organize and interpret their sensory impressions to give meaning to their environment. The perceptual process involves the perceiver, setting, and being perceived. Research on perception has consistently shown that different individuals may perceive the same thing but respond to it differently. Because in perception, the response to the perception process involves thoughts, feelings, and actions. In this case, the nurse's perception of the benefits of good discharge planning will also influence the implementation of good discharge planning.

The implementation of discharge planning cannot be separated from the responsibility of the nurses. Nurses are responsible for all forms of nursing services to patients. Based 
on this, nurses have an essential role in implementing discharge planning for patients. Its implementation requires good and directed communication so that what is conveyed can be understood and useful for the home care process. The success of the discharge planning action ensures that the patient and family can carry out safe and realistic follow-up care after leaving the hospital (Nursalam, 2014).

\section{Statement of the Problem}

In Indonesia, nursing services have designed various forms of patient discharge planning formats. The flow has been very neatly arranged to make it easier for nurses to run it as well as possible (Azimatunnisa \& Kirnantoro, 2011). Moreover, one of the discharge planning techniques used is METHOD, namely: medication, Environment, treatment, health teaching, outpatient referral, and diet (Timby, 2009). The implementation of the method should be the primary concern of health workers, especially nurses, in preparing for the patient's return.

Research regarding the evaluation of the implementation of discharge planning at Tugurejo Hospital Semarang showed that $48(46.6 \%)$ respondents were in the excellent category in carrying out discharge planning. Its shows that discharge planning at Tugurejo Hospital Semarang has not been optimally implemented (Purnamasari \& Ropyanto, 2012).

Discharge planning is a form of health service that is very important to be given to patients to improve the patient's health status after returning from the hospital. However, the implementation of Discharge Planning services in various health services is still not optimal. Given this, the researchers are interested in researching implementing nurses' perceptions of the importance of discharge planning at the RSUDZA Banda Aceh.

\section{METHODS AND MATERIALS}

The research method used is a descriptive study with a crosssectional study design through a questionnaire. The population in this study was all nurses in the inpatient room RSUDZA Banda Aceh, consisting of 122 people. The sampling method used in this research is simple random sampling, which consists of 61 respondents who were calculated using the Slovin formula.

The data collection tool in this research is a questionnaire, which consists of 2 parts, namely: Part A, in the form of respondent identity data consisting of respondent code, date of filling, and respondent demographic data. In the form of statements, Part B measures nurses' perceptions about the importance of implementing discharge planning, which consists of Medication, Environment, Treatment, Health Teaching, Outpatients Referral, and Diet (METHOD).

The following steps process the data: editing, coding, transferring and tabulating. Before the data was collected, the instrument was tested on ten nurses who work at the inpatient room Meuraxa Hospital, Banda Aceh. There were 30 valid statements for Part B questionnaires. The reliability test in this study was carried out using Cronbach's Alpha Test with a value of 0.988 so that the statements contained in the questionnaire were considered reliable (Burns \& Grove, 2005).

The research was conducted after receiving a letter of passing the ethical test from the Faculty of Nursing - Universitas Syiah Kuala Ethics Committee, which aims to protect and ensure the confidentiality of respondents. Pearson Product Moment analysis is used to determine the interaction of two variables that are thought to be related or correlated.

\section{RESULTS}

Demographic data of respondents include age, gender, nurse's education, and length of work described in Table 1 below.

Table 1: Respondents Characteristics ( $\mathrm{N}=61)$

\begin{tabular}{|c|c|c|}
\hline Characteristics & $\mathrm{f}$ & $\%$ \\
\hline Age (Depkes RI, 2009) & 10 & \\
17-25 years & 44 & 76,4 \\
26-35 years & 6 & 92,2 \\
36-45 years & 1 & 1,6 \\
46-55 years & 2 & \\
Gender & 59 & 3.3 \\
Male & & 96.7 \\
Female & 16 & 26,2 \\
\hline Nurses' Education & 4 & 6,6 \\
Ners & 1 & 1,6 \\
S1 & 40 & 65,6 \\
D-IV & 34 & \\
D-III & 19 & 55,7 \\
Length of Work & 8 & 31,1 \\
1-5 years & & \\
5-10 years & & \\
>10 years &
\end{tabular}

Based on table 1 above, it can be concluded that the majority of respondents are in the age group of 26-35 years (44 people; $72.1 \%$ ). Female respondents dominate, namely 59 people (96.7\%). For education, most respondents are Diploma-III (40 people; $65.6 \%$ ). Finally, more than half of the respondents (34 people; $55.7 \%$ ) have been worked for 1-5 years.

Nurses' perceptions about the importance of discharge planning and its sub-variables are described below.

Table 2: Frequency Distribution of Nurses Perception of the Importance of Discharge Planning and its components $(\mathrm{N}=61)$

\begin{tabular}{|l|c|c|}
\hline \multicolumn{1}{|c|}{ Variable } & $\mathrm{f}$ & $\%$ \\
\hline Discharge Planning & 41 & 67,2 \\
Importance & 20 & 32,8 \\
Less Importance & & \\
& & \\
\hline Medication & 38 & 62,3 \\
Importance & 23 & 37,7 \\
Less Importance & & \\
& & \\
\hline Environment & & \\
\hline
\end{tabular}




\begin{tabular}{|l|c|c|}
\hline \multicolumn{1}{|c|}{ Variable } & $\mathrm{f}$ & $\%$ \\
\hline Importance & 21 & 34,4 \\
Less Importance & 39 & 63,9 \\
Not Importance & 1 & 1,6 \\
\hline Treatment & 50 & 82 \\
Importance & 9 & 14,8 \\
Less Importance & 2 & 3,3 \\
Not Importance & & \\
& 21 & 34,4 \\
\hline Health Teaching & 40 & 65,6 \\
Importance & & \\
Less Importance & 53 & 86,9 \\
\hline Outpatient Referral & 8 & 13,1 \\
Importance & & \\
Less Importance & 45 & 73,8 \\
\hline Diet & 14 & 23 \\
Importance & 2 & 3,2 \\
Less Importance & & \\
Not Importance & & \\
\hline
\end{tabular}

Based on Table 2 above, it can be seen that as many as 41 nurses $(67.2 \%)$ perceive that discharge planning is important to do. Meanwhile, detail for other sub-variables can observe in the table.

\section{DISCUSSION}

Based on the research results that have been done, it can be concluded that the nurse's perception of the importance of Discharge Planning in the Inpatient Room RSUDZA Banda Aceh is "important" to implement as many as $41(67,2)$ respondents. From the result, it showed that nurse had implemented the discharge planning in necessarily.

Since the patient enters the hospital, a discharge planning program can improve health conditions and help patients achieve optimum quality of life before being discharged. Ignorance or inability of the patient and family regarding care at home will impact health and other problems. This situation can cause an increased risk of complications and results in rehospitalization (Potter \& Perry, 2012). Furthermore, failure in providing document discharge planning will risk the severity of the disease, life-threatening, and physical dysfunction. Therefore, it suggested that to run the discharge planning program for every patient. Because it can reduce the length of patient care, prevent a recurrence, improve the patient's health condition, reduce the burden on the patient's family and reduce mortality and morbidity (Nursalam, 2014). The implementation of good discharge planning will improve the patient's health quality.

Firstly, the nurse's perception about the importance of discharge planning in terms of Medication. From Table 2, more than half of respondents (38 people/62.3\%) perceive that implementing discharge planning regarding Medication is "important." This result was provoked by research that conducted by Yosafianti and Alfiyanti (2010). It shows that patient satisfaction with education preparation for discharge about drugs is $93.43 \%$. The other related studies conducted by Rahayuningsih (2014) revealed that from the time the patient was decided to go home medically until he was discharged from the ward, the waiting time was more than 3 hours. One factor that affects the delay of patients going home is preparing the patient's drug administration at home, with the percentage reaching $32.45 \%$. Other factors are that the patient does not have full insurance as much as $31.14 \%$, the family has not picked up $31.57 \%$, and the means of transportation is not yet available $14.91 \%$.

The study results found that 38 people $(62.3 \%)$ perceive that discharge planning regarding Medication looks "important" to implement. It represented that each nurse should provide information about the medication/drugs consumed by the patient to improve the patient's health. The patient should know: what drugs to continue or to stop directly after the patient back home. In this case, the nurse plays a vital role in explaining the drugs that must be continued at home after the patient leaves the hospital. A drug description usually includes the name of the drug, how to take the drug, the benefits of using the drug, and the effects. At the discharge time, the nurse gives a prescription or medicine according to the doctor's instructions.

The second variable, the importance of discharge planning according to the Environment, can be seen that most of the discharge planning regarding the Environment is "less important" to implement. The nurse considers that the condition of the patient's Environment after returning from the hospital is not the nurse's responsibility; the nurse does not have to explain how the environmental conditions around the patient will be. For safety efforts at home, nurses can be reviewed with patients and their families about environmental factors in the house that may hinder self-care, such as room size, cleanliness of the road to the door, road width, bathroom facilities, and the availability of useful tools (Potter \& Perry, 2012).

Based on the study results, it can be concluded that nurses perceive it is less important to carry out discharge planning related to the Environment. Nurses often ignore the Environment in which the patient will live after discharge from the hospital. It can be seen from the answers of respondents who stated that it was not essential to ask about the patient's bathroom facilities at home as many as 19 respondents $(31.1 \%)$. When the patient is about to leave the hospital, the nurse needs to provide information that the Environment around the patient must be safe. For example, the condition of the floor where the patient is not slippery, the bathroom is easily accessible to the patient, and things that allow falling must be avoided. The nurse must also explain to the family to pay attention to the hazardous environment that can harm the patient.

Moreover, nurses' perceptions about the importance of discharge planning related to treatment show that most nurses, namely $50(82.0 \%)$ respondents, perceive that implementing discharge planning regarding treatment is "important." Related research conducted by Lestari (2014) regarding the relationship between discharge planning and family readiness 
in carrying out health care tasks showed a significant relationship between discharge planning implementation and family readiness in carrying out tasks $\mathrm{p}$-value $=0,003$ $(\alpha=0,05)$. This result represented in health care for pulmonary tuberculosis patients in the Inpatient Room, Jember Pulmonary Hospital.

Based on the study results, it can be concluded that nurses perceive that discharge planning regarding follow-up care at home is essential to provide. When a patient is about to leave a health care unit, the nurse must ensure that patient care continues. In this case, the nurse's role is to explain what kinds of follow-up treatments the patient needs after returning home. From the respondents' answers to the questionnaire, it can be seen that as many as 42 respondents $(68.8 \%)$ stated that it is crucial to ensure that there are family members who provide follow-up care to patients when at home. In addition, the nurse can also demonstrate to the family the care that the patient needs after discharge.

The following variable to describe is discharge planning in terms of Health Teaching. Results show that more than half of respondents, namely 40 people $(65.6 \%)$, perceive that implementing discharge planning on health teaching is "less important" to do. Nurses are seemed not to provide explanations or education regarding the patient's health condition.

In a healthcare facility, the nurse's goal is to provide discharge planning education to patients to meet ongoing care needs. Successful discharge planning is a centered, coordinated, multidisciplinary process that ensures that the patient continues care after leaving the hospital (Potter \& Perry, 2012).

However, based on findings, nurses consider providing a limited education to patients who will leave the hospital. It is indicated that nurses have not carried out their duties as teachers in providing health education to patients, especially regarding their health conditions. From the respondents' answers to the questionnaire, as many as 18 respondents (29.5\%) stated that it was imperative to keep information related to complications the patient might experience after returning from the hospital. An individual is acting on their choice is primarily influenced by perception. Decision-making of action occurs as a reaction to a problem. The perception of someone who takes action will have a significant relationship (Ismainar, 2018). In this case, a nurse carrying out nursing actions is strongly influenced by how she perceives the action.

Providing health education to patients according to their needs, both during the treatment period in the hospital and at home, can minimize the risk of complications to the patient's disease. Therefore, it can speed up the healing process, shorten the patient's stay in the hospital, and help increase the patient's understanding of health, especially about the disease conditions experienced by the patient.

The fifth variable is discharge planning regarding Outpatient Referrals; from the result, it can be concluded that as many as
53 nurses $(86.9 \%)$ perceive that implementing discharge planning is "important."

Effective discharge planning often requires referral to a variety of health care disciplines. In many places, it is necessary to order health care providers to make referrals, especially when planning specific therapy, preferably patients and families are involved in decision making (Potter \& Perry, 2012).

Related research conducted by Hondro (2018) results in discharge planning to post-operative patients during treatment with percentage "Less" $81,6 \%$ and at the preparation of returning with $100 \%$ "Good" percentage. Based on the study results, it can be concluded that nurses perceive discharge planning related to outpatient referrals as essential to be given, as evidenced by as many as 53 nurses $(86.9 \%)$ perceive it to be important.

When a patient is allowed to leave a health care unit, there are several things that the patient/family must know for the continuation of patient care. Patient/family should be known: when/where to get an appointment with health services and knowing where/who can be contacted to help with the treatment. It can be seen from the respondents' answers that as many as 29 respondents $(47.5 \%)$ stated that it was imperative to provide related information on a patient's treatment schedule after discharge from the hospital. In addition, nurses must explain the place and schedule for return visits after the patient leaves the hospital and provide information about whom the patient can contact for continuity of care.

Finally, for the variable discharge planning in terms of diet, the result found that most respondents, or 45 people $(73.8 \%)$, perceive that implementing discharge planning about diet is "important." The result proves that nurses care about the food intake that patients must consume after leaving a health care unit. The nurse explains to the patient the nutritional intake that must be met and the food that must be avoided so that even though the patient has left a health care unit, he can still fulfill the appropriate intake to help improve the patient's health. From the respondents' answers to the questionnaire, it can be seen that as many as 32 respondents $(52.4 \%)$ stated that it was crucial to inform the patient of the foods that should be avoided to improve the patient's health.

In a hospital or other health care facility, the diet menu is likely to have been planned by a nutritionist. However, for the fulfillment of diet in patients who have been allowed to leave a health care unit, it is necessary to understand and know the patient/family regarding the fulfillment of dietary needs following the health problems experienced by the patient. It is indicated that nurses are responsible for providing health education to patients, including nutrition, activities/exercise, drugs, and special instructions, namely signs and symptoms of the patient's disease (Noprianty \& Noviyanti, 2019). Related research conducted by Yosafianti and Alfiyanti (2010) revealed that the level of patient satisfaction after being given health education about nutrition was $94.77 \%$, while those who 
were not given preparatory health education home by $69.04 \%$ with $\mathrm{p}$-value $=0.0001$. It shows that providing health education about nutrition for preparing patients to go home will increase patient satisfaction.

\section{CONCLUSION}

Based on the results of the research and discussion that have been described, in general, it can be concluded that the nurses' perceptions of the importance of discharge planning in the Inpatient Room of RSUDZA Banda Aceh are mainly in the "important" category (67.2\%). In particular, nurses' perceptions of the importance of Medication are primarily in the "important" category (62.3\%). In terms of the Environment, most respondents are in the "less important" category $(63.9 \%)$. Then, in Treatment $82.0 \%$ of the respondent is in "important" category. Thus, most respondents (65.6\%) were in the "less important" category in terms of Health Teaching. Moreover, for Outpatient Referrals, dominantly or $86.9 \%$ of the respondent is in "important" category. Finally, most respondents $(73.8 \%)$ are in the diet's "important" category.

For hospitals, it is expected to be input for information and consideration for the hospital to be able to improve the quality of hospital services, significantly discharge planning by making guides/permanent procedures for the implementation of discharge planning to patients; the hospital management can provide training on the implementation of discharge planning, in providing nursing care. Nurses are expected to provide maximum nursing care, especially in carrying out discharge planning to patients.

\section{DECLARATION OF CONFLICTING INTERESTS}

No conflicts of interest are reported in this study.

\section{REFERENCE}

[1] Azimatunnisa, \& Kirnantoro. (2011). The Correlation of Discharge Planning With Readiness Repatriation's Level in PKU Muhammadiyah Yogyakarta (p. 10).

[2] Burns, N., \& Grove, S. K. (2005). The Practice of Nursing Research: Conduct, Critique, and Utilization (5th ed.). Elsevier Saunders.

[3] Hariyati, R. T. S., Afifah, E., \& Handiyani, H. (2008). Evaluation of Information Technology-Based Discharge Planning Model. 12(2), 53-58.

[4] Hondro, L. K. (2018). Description of Implementation of Discharge Planning to Post-Operation's Patient Treated by Nurse in Patient Department Siloam Hospitals Dhirga Surya [Universitas Pelita Harapan]. http://repository.uph.edu/id/eprint/3446

[5] Ismainar, H. (2018). Management of work units: for medical recorders and health informatics of public health sciences nursing and midwifery. Deepublish.

[6] Kusnanto. (2004). Introduction to the Profession and Practice of Professional Nursing. In Jakarta, Penerbit Buku Kedokteran EGC.

[7] Lestari, Y. W. (2014). The Correlation Between Discharge Planning Implementation with Family Readiness to Perform Health Care Task to the Lung Tuberculosis Patient in Ward Rumah Sakit Paru Jember. Universitas Jember.

[8] Noprianty, R., \& Noviyanti, S. (2019). Implementation of Discharge Planning by Professional Care Providers in the Inpatient Room. Jurnal Kesehatan Vokasional, 4(3), 139-146.

[9] Nursalam. (2014). Nursing Management: Applications in Professional Nursing Practice. Salemba Medika.

[10] Potter, P. A., \& Perry, A. G. (2012). Fundamentals of nursing: concepts, processes, and practices. (4th ed., Vol. 2). EGC.

[11] Purnamasari, L. D., \& Ropyanto, C. B. (2012). Evaluation of the Implementation of Discharge Planning. Journal Nursing Studies, 1(1), 213-218.

[12] Rahayuningsih. (2014). Factors Affecting Delay in Discharge of Patients in the Integrated Surgical and Internal Medicine Inpatient Room Building A National Central General Hospital Dr. Cipto Mangunkusumo Jakarta. Universitas Gadjah Mada, Yogyakarta.

[13] Timby, B. K. (2009). Fundamental nursing skills and concepts. Lippincott Williams \& Wilkins.

[14] Yosafianti, V., \& Alfiyanti, D. (2010). The Effect of Health Education on Patient Discharge Preparation on Patient Satisfaction About Nursing Services at Romani Hospital Semarang. Prosiding Seminar Nasional Unimus 2010, 114-118. http://jurnal.unimus.ac.id/index.php/psn12012010/article/view/55 